\title{
Delayed effects of developmental exposure to low levels of the aryl hydrocarbon receptor agonist 3,3',4,4',5-pentachlorobiphenyl (PCB126) on adult zebrafish behavior
}

\author{
Lilah Glazer*, Mark E. Hahn and Neelakanteswar Aluru* \\ Biology Department and Woods Hole Center for Oceans and Human Health, Woods Hole \\ Oceanographic Institution, Woods Hole, Massachusetts, 02543 \\ * To whom correspondence should be addressed: Biology Department, MS\#32, Woods Hole \\ Oceanographic Institution, Woods Hole, MA 02543, USA. E-mail: Iglazer@whoi.edu; \\ naluru@whoi.edu
}

Running title: Adult behavioral effects of PCB126 developmental exposure

\begin{abstract}
Polychlorinated biphenyls (PCBs) are ubiquitous environmental contaminants. The most toxic PCBs are the non-ortho-substituted ("dioxin-like") congeners that act through the aryl hydrocarbon receptor (AHR) pathway. In humans, perinatal exposure to dioxin-like PCBs is associated with neurodevelopmental toxicity in children. Yet, the full potential for later-life neurobehavioral effects that result from early-life low level exposure to dioxin-like PCBs is not well understood. The objective of this study was to determine the effects of developmental exposure to low levels of dioxin-like PCBs on early- and later-life behavioral phenotypes using zebrafish as a model system. We exposed zebrafish embryos to either vehicle (DMSO) or low concentrations of PCB126 $(0.3,0.6,1.2 \mathrm{nM})$ for 20 hours (4-24 hours post fertilization), and then reared them to adulthood in clean water. Locomotor activity was tested at two larval stages ( 7 and 14 days post fertilization). Adult fish were tested for anxiety-related behavior using the novel tank and shoaling assays. Adult behavioral assays were repeated several times on the same group of fish and effects on intra- and inter-trial habituation were determined. While there was no effect of PCB126 on larval locomotor activity in response to changes in light conditions, developmental exposure to PCB126 resulted in impaired short- and long-term habituation to a novel environment in adult zebrafish. Cyp1a induction was measured as an indicator for AHR activation. Despite high induction at early stages, cyp1a expression was not induced in the brains of developmentally exposed adult fish that showed altered behavior, suggesting that AHR was not activated at this stage. Our results demonstrate the effectiveness of the zebrafish model in detecting subtle and delayed behavioral effects resulting from developmental exposure to an environmental contaminant.
\end{abstract}

Keywords: Zebrafish, PCB126, dioxin, developmental neurotoxicity, anxiety, habituation 


\section{Introduction}

There is increasing concern regarding the life-long neurotoxic effects of developmental exposure to environmental contaminants at levels that do not result in acute toxicity (Connors et al., 2008, Grandjean and Landrigan, 2006, 2014, Heindel and Vandenberg, 2015, Lupien et al., 2009). A group of chemicals implicated in such effects are 2,3,7,8tetrachlorodibenzo-p-dioxin (TCDD, "dioxin") and non-ortho ("dioxin-like") polychlorinated biphenyls (PCBs), ubiquitous contaminants that are present in up to $\mathrm{ng} / \mathrm{g}$ (lipid-adjusted) quantities in human cord blood and breast milk samples, suggesting fetal or in utero exposure to low levels during early development (Crinnion, 2011, Huisman et al., 1995, Park et al., 2010, Patandin et al., 1999, Schantz et al., 2003). A growing number of epidemiological studies conducted worldwide demonstrate association between prenatal and perinatal (maternal) exposure to dioxins and dioxin-like PCBs and neurobehavioral effects such as poorer short-term memory and attention, reduced IQ, and cognitive impairment in infants and children (Crinnion, 2011, Grandjean and Landrigan, 2006, Huisman et al., 1995, Jacobson and Jacobson, 1996, Jacobson et al., 1990, Landrigan, 2001, Patandin et al., 1999, Schantz et al., 2003, Vreugdenhil et al., 2002). In some cases the effects were still measurable in school-age children even though exposure levels declined substantially after weaning, suggesting that the neurotoxicity associated with prenatal exposure may have long-term implications. These findings are further supported in a number of mammalian studies demonstrating that developmental exposure to dioxins and dioxin-like PCBs resulted in impairment of advanced brain functions such as learning and memory, deficits in socioemotional behavior, and increased anxiety in response to mild stress, occurring at the juvenile and/or adult stages (Hany et al., 1999, Jolous-Jamshidi et al., 2010, Kakeyama et al., 2014, Kakeyama and Tohyama, 2003, Nguyen et al., 2013a, Orito et al., 2007, Piedrafita et al., 2008, Schantz and Widholm, 2001, Zimmer et al., 2009). However, the full potential for later-life neurobehavioral effects that result from early-life low level exposure to dioxin-like compounds is not well understood.

Zebrafish are increasingly used as a tool to study the life-spanning neurobehavioral effects of vertebrate developmental neurotoxicity (Bailey et al., 2013, de Esch et al., 2012a, Lee and Freeman, 2014a, Tierney, 2011). A diverse set of protocols for behavioral testing are available and the variety of endpoints that can be tested continues to grow. Adult zebrafish can be reliably tested for a large set of phenotypes including aggression, reproductive behavior, social behavior, anxiety, learning, memory and habituation (Bailey et al., 2015, Kalueff and Cachat, 2011a, b, 2012, Stewart et al., 2012). Even relatively subtle behavioral effects can be detected and quantified. Furthermore, testing for behavioral endpoints in zebrafish can be performed from as early as the larval stages shortly after 
hatching, through the juvenile and adult stages, enabling accurate timing of phenotype occurrence and persistence. Although most of the zebrafish studies on the long-term effects of developmental chemical exposure have focused on adult behavior (Lee and Freeman, 2014b, Levin et al., 2003, Levin et al., 2011), a few investigators have taken advantage of the zebrafish model to look at neurobehavioral effects over multiple life-stages (Eddins et al., 2010, Pean et al., 2013).

In the present study we exposed zebrafish embryos to the dioxin-like PCB126 at concentrations that were previously shown to be below those required to induce the typical embryotoxic effects of dioxin-like compounds, such as pericardial edema, craniofacial malformations, impaired circulation and reduced swim bladder inflation (Jonsson et al., 2007a, Jonsson et al., 2012). When the fish reached larval stages, we tested their locomotor activity in response to changes in lighting conditions, in order to identify any immediate or short-term behavioral effects caused by the low-level developmental exposure. In adult fish, we tested for effects on social and individual anxiety-related behaviors using the shoaling and novel tank assays, respectively. By repeating the assays over several weeks, we further examined the ability of the adult fish to undergo short- and long-term habituation to a novel environment. 


\section{Materials and methods}

Experimental animals and breeding stock husbandry

All the experiments were conducted using the Tupfel/Long fin (TL) wild-type strain of zebrafish. Fish were maintained in the Woods Hole Oceanographic Institution zebrafish facility, and the experimental procedures were approved by the Institutional Animal Care and Use Committee. Adult zebrafish were held in 2:1 female to male groups at a density of $\leq 5$ fish/l in 3 or 10 I tanks in a recirculating flowing water system (Aquatic Habitats Inc., Apopka, FL, USA) filled with system water (475 mg/l Instant Ocean, $79 \mathrm{mg} / \mathrm{l}$ sodium bicarbonate and $53 \mathrm{mg} / \mathrm{l}$ calcium sulfate). Illumination was set to $14: 10 \mathrm{~h}$ light:dark cycle and water temperature was kept at $28.5^{\circ} \mathrm{C}$. The fish were fed twice daily; morning feeding with brine shrimp (Artemia salina) and afternoon feeding with GEMMA Micro 300 micro-pellets (Skretting USA, Tooele, Utah). Fertilized eggs were obtained by group breeding in tanks containing 30 females and 15 males.

\section{Developmental PCB126 exposure}

Fig. 1 shows the experimental timeline of embryonic exposure and subsequent experiments. Freshly fertilized embryos were placed in 0.3X Danieau's solution pH 7.4 (17 $\mathrm{mM} \mathrm{NaCl}, 0.2 \mathrm{mM} \mathrm{KCl}, 0.12 \mathrm{mM} \mathrm{MgSO}_{4}, 0.18 \mathrm{mM} \mathrm{Ca}\left(\mathrm{NO}_{3}\right)_{2}$ and $1.5 \mathrm{mM}$ HEPES free acid $\mathrm{pH}$ 7.6). At 4 hours post fertilization (hpf) the embryos were transferred to glass petri dishes containing Danieau's solution added with $0.04 \%$ DMSO alone (vehicle control) or 0.01 $0.04 \%$ DMSO containing one of the following concentrations of PCB126; $0.3 \mathrm{nM}, 0.6 \mathrm{nM}$ or $1.2 \mathrm{nM}$. Three glass petri dishes were set up as replicates for each treatment, and each replicate dish consisted of 15 embryos in $30 \mathrm{ml}$ exposure solution. At $24 \mathrm{hpf}$ the exposure solution was removed and the embryos were washed three times with fresh Danieau's solution before they were transferred to large plastic petri dishes. Three independent exposure experiments were conducted in this study using embryos from three separate breeding events. Table 1 presents details on the treatments conducted in each exposure as well as subsequent experiments (RNA extraction and behavioral testing). Exposure 1 was terminated at $24 \mathrm{hpf}$, when embryos were sampled for RNA extraction. Exposure 2 was terminated at 7 days post fertilization (dpf) following larval locomotor activity testing.

Exposure 3 was followed by sampling at $120 \mathrm{hpf}$ for RNA extraction, larval locomotor activity testing at $14 \mathrm{dpf}$ and adult behavioral testing when the fish reached 4 months of age. In exposure 3, a non-exposed control was also included. No significant morphological defects were observed in the embryos and larvae in any of the exposure concentrations used in this study. 
Embryos were reared at $28^{\circ} \mathrm{C}$ under a 14:10 h light:dark cycle in Danieau's solution, and water was exchanged every two days. The embryos were examined daily, and any dead or malformed embryos were removed. At $120 \mathrm{hpf}$, larvae were either sampled for RNA extraction (exposure 3) or transferred into 1 I tanks (replicates were kept separate) with system water and fed with rotifers every two days. At $14 \mathrm{dpf}$, subsets of larvae from each treatment group were subjected to larval locomotor activity assays (see below). At this stage all the replicates were pooled and raised to adulthood in 9.5 I glass tanks (30.5x15.2x20.3 $\mathrm{cm}, \mathrm{HxWxL}$ ) equipped with heaters and aeration and kept at $28 \pm 2{ }^{\circ} \mathrm{C}$ under ambient light conditions. Juvenile and adult fish were fed daily with freshly hatched brine shrimp.

\section{Larval locomotor activity testing}

Larval locomotor activity was assessed at $7 \mathrm{dpf}$ and $14 \mathrm{dpf}$ (Fig. 1 and Table 1) using a DanioVision $^{\mathrm{TM}}$ behavior system (Noldus Information Technology, Inc., The Netherlands). At $7 \mathrm{dpf}$ a total of $\mathrm{n}=24-27$ larvae per treatment were tested in three 48 -well plates. Each plate contained larvae from all three replicates of all treatment groups (8-9 larvae per treatment), and the plates were tested sequentially in the course of one afternoon. At $14 \mathrm{dpf}$, one plate was assayed with $n=8$ larvae per treatment. In order to acclimate the larvae to testing conditions, individual larvae were transferred into 48-well plates twenty-four hours prior to testing. Larvae were dark adapted for at least two hours before trial initiation by first covering the plates with aluminum foil (placed in an incubator at $28^{\circ} \mathrm{C}$ ) until about $1 \mathrm{~h}$ before trial initiation when the plates were placed in the testing system (in the dark). Fish movements were recorded using the EthoVision software (Noldus, Inc.) for a total of 42 min with the following incubations and transitions of lighting conditions; 1) dark incubation for 5 min (preceded by dark incubation as detailed above), 2) transition from dark to $50 \%$ light (measured illuminance - 1250 lux), 3) 50\% light incubation for 15 min, 4) transition from 50\% light to $100 \%$ light (measured illuminance - 2500 lux), 5) 100\% light incubation for 15 min, 6) transition from $100 \%$ light to dark, and 7) dark incubation for $7 \mathrm{~min}$. The above testing protocol was aimed at evaluating two main parameters; locomotor activity during different light conditions, and changes in locomotor activity in response to transitions between light conditions. Locomotor activity was recorded at a rate of 30 frames per second, and a track smoothing protocol was applied based on 10 samples before and after every sample point in order to exclude slight movements that might introduce noise to the calculations. All behavior assays were conducted between 13:00-17:30 h. Water temperature was maintained at $28^{\circ} \mathrm{C}$ using a temperature control unit. Total distance moved is reported in centimeters $(\mathrm{cm})$ per 1 min interval. Illuminance in the DanioVision ${ }^{\mathrm{TM}}$ chamber was measured using a standard digital light meter (Nubee ${ }^{\circledR}$ NUB1010B) with an accuracy of $\pm 5 \%$ at room temperature. 


\section{Adult behavior testing}

Adult behavioral assays were conducted at 4 months of age, using the same groups of fish tested at $14 \mathrm{dpf}$ (Table 1 and Fig. 1). The total numbers of fish in each treatment group were 9, 10, 14, 10 and 8 in non-exposed, vehicle control, $0.3 \mathrm{nM}, 0.6 \mathrm{nM}$ and $1.2 \mathrm{nM}$ PCB126 groups respectively. Two types of assays for anxiety-related behaviors were conducted - a shoaling assay and a novel tank assay. For both assays the fish from each treatment group were placed in separate holding tanks and allowed to acclimate to the testing room for $4 \mathrm{~h}$ prior to beginning of trials.

Shoaling assay. This assay tests how changes in the state of anxiety might affect fish shoaling cohesion. The assay was conducted as described previously (Parker et al., 2013) with some modifications. Briefly, a rectangular tank was placed on a grid dividing its bottom surface into 8 equal sections and filled with water up to a height of $6 \mathrm{~cm}$, and a digital video camera (WV-BP330 series, Panasonic Corporation) was secured to a ring stand so that the entire tank could be filmed from above. Testing was conducted in 'runs', in which groups of five fish were removed from a holding tank (treatment groups were kept in separate holding tanks) and placed in the testing tank. The fish were allowed to acclimate to the tank for 5 min and then recorded for a duration of $10 \mathrm{~min}$. At the end of the run, the fish were returned to the same holding tank ${ }^{1}$. Four or five runs were conducted for each treatment group ${ }^{2}$, and the treatment groups were alternated to allow for a resting period between runs. Two shoaling assays (trials) were conducted with the same set of fish separated by a 2.5 weeks interval. Group cohesion was evaluated in each run using the following cluster score calculationCluster score $=\frac{\text { Maximum number of fish in one section }}{\text { Total number of sections occupied by fish }}$

A cluster score was manually determined once every $30 \mathrm{sec}$ during the 10 min recording (total of 20 cluster scores per run) and a mean cluster score was calculated for each run.

Novel tank assay. The novel tank test measures anxiety-related behavior following introduction into an unfamiliar environment. It was conducted as described previously (Cachat et al., 2010) with some modifications. Briefly, fish were individually introduced to the test tank and immediately video recorded from the side for 10 min using a digital video camera. Data were analyzed using EthoVision software (Noldus Information Technology, Inc.). The amount of time spent in the pre-defined 'bottom zone' was calculated, as well as

\footnotetext{
${ }^{1}$ Due to the number of adult fish that were available, we could not pre-divide each treatment group to sub-groups of 5 fish. Therefore, during our sampling of fish from the holding tank in each run it was inevitable that some of the fish were re-sampled.

${ }^{2}$ In trial 1, 5 runs were conducted from all treatment groups. In trial 2, 4 runs were conducted from the vehicle control and $0.3 \mathrm{nM}$ PCB126-exposed groups, and 5 runs from the $0.6 \mathrm{nM}$ and $1.2 \mathrm{nM}$ PCB126-exposed groups.
} 
the latency to transition to the upper zone for the first time. Three independent trials were conducted on the same fish with two-week intervals before the second and third trials. The number of individuals tested from each treatment group varied slightly between trials, as detailed in Table 2.

Embryo, larvae and adult brain sampling and RNA extraction

Pools of 18 embryos (24 hpf,) or 15 larvae (120 hpf) were sampled from each treatment replicate (see exposure protocol above). Brain tissue was dissected from adult fish after completion of behavioral testing. Samples were flash-frozen in liquid nitrogen and stored in $-80^{\circ} \mathrm{C}$ until total RNA was isolated. Total RNA was isolated either following a protocol for simultaneous isolation of DNA and RNA (Pena-Llopis and Brugarolas, 2013) (24 hpf and adult brain samples) or using the Aurum ${ }^{\mathrm{TM}}$ Total RNA Mini Kit (Bio-Rad, Hercules, CA; 120 hpf samples).

\section{Cyp1a relative quantification}

Complementary DNA was synthesized from total RNA using iScript ${ }^{\mathrm{TM}}$ cDNA Synthesis Kit (Bio-Rad) from $1 \mu \mathrm{g}$ total RNA. Quantitative real-time PCR was carried out using the iQ SYBR Green Supermix (Bio-Rad) in a CFX96 Touch $^{\text {TM }}$ Real-Time PCR Detection System (Bio-Rad). The PCR conditions used were $95^{\circ} \mathrm{C}$ for 3 min and $95^{\circ} \mathrm{C}$ for $15 \mathrm{~s} / 65^{\circ} \mathrm{C}$ (primer annealing temperature) for $30 \mathrm{~s}$ (40 cycles). The primers used to amplify different transcripts were; Cyp1a Forward- 5'-GCATTACGATACGTTCGATAAGGAC-3' and Cyp1a Reverse- 5'GCTCCGAATAGGTCATTGACGAT-3', $\beta$-actin Forward- 5'-

CAACAGAGAGAAGATGACACAGATCA-3' and $\beta$-actin Reverse- 5 GTCACACCATCACCAGAGTCCATCAC-3'. Each PCR reaction was run in triplicate and a no-template control reaction was run on each PCR plate. Melt curve analysis was performed at the end of each PCR run to ensure that no nonspecific products are amplified. Relative levels of transcript abundance were calculated using the $2^{-\Delta \Delta C t}$ method (where $\Delta \Delta C t=$ $\left[\mathrm{Ct}_{(\mathrm{GOI})}-\mathrm{Ct}_{(\beta \text {-actin) }}\right] \mathrm{PCB} 126-\left[\mathrm{Ct}_{(\mathrm{GOI})}-\mathrm{Ct}_{(\beta \text {-actin) }}\right] \mathrm{DMSO}$ (GOI, gene of interest; (Livak and Schmittgen, 2001)).

\section{Statistical analysis}

Larval locomotor activity was analyzed with repeated measures two-way analysis of variance (ANOVA), with treatment and time as independent variables, and distance moved in $\mathrm{cm}$ per minute as the dependent variable. At $7 \mathrm{dpf}$, the data from all three plates were analyzed together.

Shoaling cluster scores were analyzed in two steps. First, a Linear Mixed Effects (LME) model was constructed for each of the two trials. Treatment (vehicle control and PCB126 exposure concentrations) was set as the fixed effect, time (20 cluster scores calculated 
every $30-\mathrm{sec}$ in each 10-min run) as a covariate, and the runs (groups of 5 fish sampled from each treatment 4-5 times) as the random effect with random intercepts and random slopes by time. A null model was also constructed without the effect of treatment and a Likelihood Ratio Test (LRT) was used to test the significance of the relationship between treatment and cluster score. The LME analysis was followed with two-way ANOVA (not repeated measures), with treatment and trial as independent variables and mean cluster score (calculated for each run) as the dependent variable. Uncorrected Fisher's LSD post-hoc test was used to determine any significant treatment or trial effect.

Novel tank mean percent time in bottom zone, mean latency to upper zone and total distance travelled (calculated for the entire $10 \mathrm{~min}$ of each trial) were analyzed with two-way ANOVA, with treatment and trial as independent variables, and the calculated parameters as the dependent variables. If an interaction between treatment and trial was significant, uncorrected Fisher's LSD post-hoc test was performed to determine any significant effect of treatment and trial. The percent time in bottom zone per 2-min was analyzed separately for each trial with a repeated measures two-way ANOVA, with treatment and time as independent variables and percent time in bottom zone per 2-min as the dependent variable. If an interaction between treatment and time was significant, a Bonferroni post-hoc test was performed to determine which PCB126 treatments were different from the vehicle control at each 2-min time segment.

Cyp1a relative expression data were analyzed separately for each sampling stage to determine significant differences between PCB126-exposed and vehicle control groups. The $24 \mathrm{hpf}$ and adult brain data were analyzed with unpaired t-test, and the $120 \mathrm{hpf}$ data were analyzed with a one-way ANOVA, with treatment as the independent variable and relative fold change $\left(2^{-\Delta \Delta C t}\right)$ as the dependent variable. A post-hoc uncorrected Fisher's LSD test was performed to determine significant difference from the vehicle control.

LME and LRT were performed in $R$ ( $R$ Core Team, 2015, version 3.2.2). ANOVA was performed in GraphPad Prism (GraphPad Software Inc., version 6.07). Significance was set at $p<0.05$. Detailed statistical information ( $X^{2}, F$-statistics and $P$ values) is presented in the figure captions. All data are presented as mean \pm standard error of mean (S.E.M). 


\section{Results}

Larval behavior: locomotor activity

Developmental PCB126 exposure did not have a significant effect on larval locomotor activity when compared to the vehicle control either at $7 \mathrm{dpf}$ (Fig. 2A) or $14 \mathrm{dpf}$ (Fig. 2B). All larvae in each age group displayed similar responses to the lighting transitions (grey boxes) as well as similar levels of activity during incubations in different lighting conditions.

Repeated measures two-way ANOVA was conducted for each larval stage. At $7 \mathrm{dpf}$, an expected effect of time $\left(\mathrm{F}_{(41,4141)}=123.7, p<0.0001\right)$ was found, however there was no effect of treatment $\left(\mathrm{F}_{(3,101)}=0.3276, p=0.8054\right)$ or interaction between treatment and time $\left(F_{(123,4141)}=0.9884, p=0.5197\right)$ (Fig. 2A). Similarly, at $14 \mathrm{dpf}$ an effect of time $\left(F_{(41,1148)}=\right.$ $41.14, p<0.0001)$ was found, while there was no effect of treatment $\left(\mathrm{F}_{(3,28)}=0.09620, p=\right.$ $0.9615)$ or interaction between treatment and time $\left(\mathrm{F}_{(123,1148)}=0.6835, p=0.9961\right)$ (Fig. 2B). Subject matching was significant in both larval stages $(p<0.0001)$.

Adult behavior: shoaling

The experimental set-up used for testing of adult shoaling behavior, and examples of high and low clustering and cluster score calculations are demonstrated in Fig. 3A. The shoaling behavior assay was conducted two times (trials) with the same fish (Fig. 3B; trial 1 and trial 2); a 2.5-week interval separated the two trials. Likelihood Ratio Tests performed for LME models revealed a significant effect of treatment in Trial $1\left(X^{2}=18.43, p<0.001\right)$ but not in Trial $2\left(X^{2}=4.9556, p=0.1751\right)$. Two-way ANOVA revealed a significant effect of both treatment $\left(\mathrm{F}_{(3,30)}=7.032, p=0.001\right)$ and trial $\left(\mathrm{F}_{(1,30)}=13.87, p<0.001\right)$, but no interaction between treatment and trial $\left(\mathrm{F}_{(3,30)}=0.9869, p=0.4122\right)$. In trial 1 , the fish that were exposed to the lowest concentration of PCB126 (0.3 nM) showed a significantly increased mean cluster score compared to all other treatment groups (vehicle control, $p<0.05 ; 0.6 \mathrm{nM}$ $p<0.05 ; 1.2 \mathrm{nM}, p<0.001)$. In trial 2 , the mean cluster score of the same fish $(0.3 \mathrm{nM})$ significantly decreased compared to trial $1(p<0.01)$, but was still higher than that of the 1.2 nM PCB126-exposed group $(p<0.05)$. A slight trend towards a reduction in mean cluster score from trial 1 to trial 2 was also observed for the other treatment groups; however, it was not statistically significant.

Adult behavior: novel tank

We performed the novel tank assay three times (trials) at intervals of two weeks between trials. Two characteristic measures of anxiety-related behavior-the percent of time spent in the bottom zone (Fig. 4A) and the latency to enter the upper zone for the first time (Fig. $4 \mathrm{~B}$ ) - were calculated for the entire duration of each trial (10 minutes) and averaged for all individuals in each experimental group. The effects of both PCB treatment and assay 
repetition (trials) on the percent of time spent in the bottom zone were tested using two-way ANOVA. A significant effect of treatment was found $\left(\mathrm{F}_{(3,105)}=23.79, p<0.0001\right)$ as well as an interaction between treatment and trial $\left(\mathrm{F}_{(6,105)}=4.588, p<0.001\right)$, but no significant effect of trial alone $\left(\mathrm{F}_{(2,105)}=2.120, p=0.1251\right)$. A decrease in the percent of time spent in the bottom zone from trials 1 and 2 to trial 3 was observed in the vehicle control fish $(p<$ 0.001) (Fig. 4A). In contrast, the percent of time spent in the bottom zone by all PCB126exposed fish remained high during all three trials, and was markedly higher than the vehicle control in trials $2(0.3 \mathrm{nM}, p<0.01 ; 0.6 \mathrm{nM} p<0.05 ; 1.2 \mathrm{nM}, p<0.001)$ and $3(p<0.0001)$.

The latency (in seconds, s) to enter the upper zone was also analyzed using two-way ANOVA, revealing a significant effect of treatment $\left(\mathrm{F}_{(3,106)}=3.131, p<0.05\right)$ as well as an interaction between treatment and trial $\left(\mathrm{F}_{(6,106)}=2.962, p<0.05\right)$, but no significant effect of trial alone $\left(\mathrm{F}_{(2,106)}=0.9075, p=0.4066\right)$. In trials 2 and 3 of the assay, the vehicle control fish exhibited a shortening of the latency to enter the upper zone $(p<0.05)$ (Fig. 4B). A similar pattern was observed in the $0.6 \mathrm{nM}$ PCB126-exposed group, although it did not achieve statistical significance. In contrast, the $0.3 \mathrm{nM}$ and $1.2 \mathrm{nM}$ PCB126-exposed fish maintained high mean latencies, that were significantly higher than the vehicle control $(0.3 \mathrm{nM}, p<$ $0.001 ; 1.2 \mathrm{nM}, p<0.01)$. In addition, the mean latency of the $0.3 \mathrm{nM}$ PCB126-exposed group increased in Trial 3 compared to Trial $2(p<0.05)$, and the mean latency of the $1.2 \mathrm{nM}$ PCB126-exposed group increased in Trial 3 compared to Trial $1(p<0.05)$.

A closer look at the percent of time spent in the bottom zone in 2 minute segments (Fig. $5 A$ ) reveals that all PCB126 exposed groups spent more than $50 \%$ of all segments in the bottom zone in all three trials, without any significant change in behavior during the trials. In contrast, the control group not only reduced the total percentage of time in the bottom zone, but also showed a change in behavior during the progress of the second and third trials by gradually increasing the time spent in the bottom zone. Repeated measures two-way ANOVA was conducted for each trial separately. In trial 1 no effect was found for either treatment $\left(\mathrm{F}_{(3,33)}=1.119, p=0.3554\right)$, time $\left(\mathrm{F}_{(4,132)}=1.218, p=0.3063\right)$ or the interaction between treatment and time $\left(\mathrm{F}_{(12,132)}=0.6469, p=0.7986\right)$. In trial 2 , a significant effect of treatment was found $\left(\mathrm{F}_{(3,34)}=7.25, p<0.001\right)$ as well as an interaction between treatment and time $\left(F_{(12,136)}=3.241, p<0.001\right)$, but no effect of time alone $\left(F_{(4,136)}=0.4954, p=\right.$ $0.7391)$. In trial 3 the difference in behavior between the PCB126 and vehicle-exposed fish became highly pronounced, as can be visualized in Fig. 5B, showing representative traces of the first 2 minutes from each experimental group. This was followed by a Bonferroni posthoc test, revealing a significant difference for all of the PCB126-exposed groups from the vehicle control in the first four minutes, and for the lowest $(0.3 \mathrm{nM})$ and highest (1.2 $\mathrm{nM})$ exposures up to minute six. In trial 3 , a significant effect of treatment was identified $\left(F_{(3,37)}=\right.$ 
37.67, $p<0.0001)$, but no effect of time $\left(\mathrm{F}_{(4,148)}=1.723, p=0.1479\right)$ or an interaction between treatment and time $\left(F_{(12,148)}=1.425, p=0.1606\right)$.

Total distance travelled during the entire 10-min duration of testing was calculated for each fish and averaged within each treatment group. In trials 1 and 3 , a non-exposed control group of fish was also tested. One-way ANOVA was conducted for each trial separately, revealing significant differences between treatment groups in Trial $2\left(\mathrm{~F}_{(3,34)}=7.747, p<\right.$ $0.001)$ and Trial $3\left(F_{(4,45)}=5.942, p<0.001\right)$, but not in Trial $1\left(F_{(4,41)}=1.495, p=0.2215\right)$.

As can be seen in Fig. 6 , in trial 1 all treatment groups had similar activity levels indicated by the similarity in mean distance travelled. In trial 2 however, the $0.6 \mathrm{nM}$ and $1.2 \mathrm{nM}$ PCB126exposed groups had increased activity compared to the vehicle control $(p<0.05)$ and the $0.3 \mathrm{nM}$ PCB126-exposed group $(p<0.001)$. In trial 3 , there was a staggered pattern of activity, with the non-exposed control and the $0.3 \mathrm{nM}$ and $1.2 \mathrm{nM}$ PCB126-exposed groups having similarly reduced activity compared to the vehicle control and 0.6 nM PCB126exposed groups $(p<0.01)$.

\section{Cyp1a levels}

To assess the persistence of AHR activation following developmental exposure to PCB126, we measured the induction of the marker gene cyp1a by qRT-PCR in zebrafish embryos immediately following exposure termination (24 hpf, whole embryos), at the early larval stage of $120 \mathrm{hpf}$ (whole larvae), and in adult brain tissue shortly after completion of behavior assays. Cyp1a expression was induced in $24 \mathrm{hpf}$ embryos exposed to PCB126 concentrations as low as $0.3 \mathrm{nM}(p<0.01)$ (Fig. 7). In $1.2 \mathrm{nM}$ PCB126-exposed fish the induction continued at least until $120 \mathrm{hpf}(p<0.05)$, indicating the presence of PCB126 in the larvae and/or sustained activation of AHR. However, cyp1a was not induced in the brains of the developmentally exposed adult fish that showed lack of habituation to the novel tank assay. These results suggest that, at the time of behavioral testing of these adults, PCB126 levels in the brain tissue in these fish were below those required for activation of AHR. 


\section{Discussion}

Here we show that exposure of zebrafish embryos to the dioxin-like PCB126, at levels below those causing overt developmental toxicity, resulted in lack of long- and short-term habituation to a novel environment in adults, as observed in the novel tank assay. In zebrafish, the novel tank assay is used to test the behavior of individuals in response to the stress-promoting situation of introduction to a novel environment. In this assay we normally expect to see an initial diving to the bottom of the tank accompanied by reduced exploration. This behavior was shown to be lessened in the short-term (intra-session, minutes) and longterm (inter-session, days) through exposure prolongation as well as subsequent repetitions of the test, in a process called habituation (Wong et al., 2010). Habituation is a form of nonassociative learning and refers to the reduction in an individual's behavioral response to a stimulus following recurrence of that stimulus (Thompson and Spencer, 1966). In relation to the stimulus of a novel environment, habituation involves spatial learning and memory (Leussis and Bolivar, 2006). In the present study, long-term impairment in habituation was clearly seen where all of the PCB126-treated fish displayed high anxiety-related behavior throughout all of the novel tank assay trials, while the reaction of the vehicle control fish was markedly reduced by the second and third trials. The short-term lack of habituation was made clear by visualizing within-trial behavioral patterns, when a gradual increase in bottom zone time was observed for the vehicle control fish in the second and third trials. This pattern of behavior might be indicative of a natural preference of zebrafish to seek safety in the lower area of the water column once they have explored its upper area, and is a feature of short-term habituation and spatial memory. In contrast, all of the PCB126-exposed fish lacked any within-trial change in behavior and maintained a clear preference for the lower area of the testing tank throughout each trial, therefore indicating impairment in short-term habituation.

Impaired habituation to a novel environment is hypothesized to be a feature of pathological (non-adaptive) anxiety (Salomons et al., 2010). Wong et al (2010) tested this hypothesis on zebrafish intra-session (short-term) habituation to the novel tank assay using pentylenetetrazole (PTZ) and caffeine as known anxiogenic drugs, and found that habituation was strongly attenuated by acute exposure to either drug. Orito et al. (2007) tested for effects of prenatal exposure to PCB126 on anxiogenic behavior in young (prepuberty) rats using the open field and social interaction tests. The open field test, similar to the novel tank assay, is a stress-promoting situation with subjects tested individually, while the social interaction test examines interactive behavior of the tested subject with a novel partner as a measure for general anxiety level. In both assays, PCB126 exposure was associated with anxiogenic behavioral responses. In the shoaling assay, we looked at 
shoaling cohesion as a measure for the general anxiety level in the different treatment groups. In this assay we expected that increased general anxiety will lead to an increase in group cohesion and therefore to higher overall cluster scores. The increased shoaling cohesion of the $0.3 \mathrm{nM}$ PCB126-exposed fish in the first trial may indicate an anxiogenic effect at lower levels of exposure, however this difference did not persist in the second trial. Thus, our results cannot provide clear support to conclude that PCB126-induced lack of habituation is a consequence of increased general anxiety level. Taking into account that we re-sampled the same groups of fish in different runs of the assay, it might be that the effect of the toxicant was masked in some treatment groups by dominant individuals that affected group shoaling behavior in multiple runs. Consequently, conducting the shoaling assay following pre-separation of the fish from each treatment group into designated shoals might reveal a more distinct effect of PCB126-exposure on shoaling cohesion and therefore on the general anxiety level of the fish.

A number of studies in monkeys as well as rodent models have shown that perinatal exposure to low levels of mixtures of PCBs (including dioxin-like and non-dioxin-like congeners) causes long-term impairment in spatial learning alone or both learning and memory (reviewed by Schantz and Widholm, 2001). In contrast to the mixture studies, when either monkeys or rats were exposed only to dioxin or dioxin-like (coplanar) PCBs, the treated animals showed no difference in spatial learning and in some cases even performed better than controls (Schantz and Widholm, 2001). However when non-spatial cue-based learning was tested, it was found to be impaired in the dioxin-exposed animals compared to the controls (Schantz and Bowman, 1989, Schantz and Widholm, 2001, Seegal and Schantz, 1994, Seo et al., 1999). Interestingly, a recent study evaluating paired-associate learning in rat offspring that were prenatally exposed to dioxins found that the exposure not only caused impairment in task performance but also induced anxiety-like behavior (Kakeyama et al., 2014). Thus, the effects of developmental PCB exposure on learning and other behavioral endpoints are complex and likely to be congener-dependent.

To date, repetitive testing of learning and memory in adult zebrafish has been mostly limited to either same-day training and trials or testing over a period of up to a few days (AlImari and Gerlai, 2008, Eddins et al., 2010, Maaswinkel et al., 2013, Ninkovic and Bally-Cuif, 2006, Xu et al., 2012). The first study to systematically evaluate habituation in zebrafish was performed by Wong et al (2010). In that study, the novel tank assay was used in order to test intra- and inter-session habituation to novelty. The inter-session testing was performed by repeating the novel tank assay daily over a period of seven days. In our study, we examined inter-session habituation with two-week intervals between trials, and found that despite the significantly longer inter-session intervals, habituation still occurred in our control fish. This 
finding shows that zebrafish have the ability to learn over much longer time periods than have been tested so far. Consequently, our results not only stress the importance of trial repetition and extended inter-trial intervals for revealing the full extent of neurobehavioral outcomes, but also strengthen zebrafish utility as a behavioral model for investigating processes of learning and memory.

A previous study showed that exposure of zebrafish embryos (at 2-4 dpf) to sub-lethal levels of dioxin resulted in a decrease in critical swimming speed in 90 days-old adults (Marit and Weber, 2012). Consequently, the increase in bottom zone time and latency to transition to upper zone observed in our studies might have been caused by a general reduction in movement of the fish. However, when we calculated the mean total distance traveled for each experimental group, no correlation was found between the levels of anxiety-related behaviors and overall movement of the fish (Fig. 6), suggesting the apparent anxiety-related behavior is not an artifact of decreased movement. Additionally, following a recent report of impaired active avoidance learning in adult zebrafish developmentally exposed to $0.1 \%$ DMSO (Truong et al., 2014a), we included a non-exposed group of fish that was also tested in trials 1 and 3. Non-exposed zebrafish showed a long-term behavioral pattern similar to that of the vehicle control fish that were exposed to $0.04 \%$ DMSO (supplementary fig. S1A and $B$ ), demonstrating that at the concentrations used in our experiments, DMSO did not cause behavioral effects.

In the present study we exposed zebrafish embryos to levels of PCB126 that were lower than those causing immediate embryotoxicity. We then measured larval locomotor activity in response to changes in lighting conditions, in order to investigate whether neurotoxicity can be detected as early as 7 or $14 \mathrm{dpf}$, but did not identify any significant differences between PCB126-exposed fish and vehicle controls. Zebrafish larval locomotor activity is widely used in recent years as a reliable, sensitive and high throughput method for neurotoxicity assessment (Cowden et al., 2012, de Esch et al., 2012b, Irons et al., 2013, MacPhail et al., 2009, Selderslaghs et al., 2013, Truong et al., 2014b). It is suggested that larval activity may be used as a complementary method alongside other approaches such as in vitro testing for identifying potentially neurotoxic chemicals (Truong et al., 2014b). Based on our results we propose that in some cases neurotoxicity caused by low level exposure may not be detected at the larval stages using the locomotor activity assay. Hence, testing at multiple life-stages and looking at different behavioral end-points are required in order to identify the accurate timing of phenotype appearance and its specific nature. It should be noted that the testing at $14 \mathrm{dpf}$ was performed with a relatively small number of larvae in each treatment group, and therefore the statistical power of the analysis was not high. Our behavioral results are further supported by the lack of cyp1a induction in the adult brain. Cyp1a induction is a sensitive 
indicator of AHR activation resulting from exposure to dioxin-like compounds. PCB126 induces cyp1a expression in zebrafish embryos via activation of AHR, in a concentrationdependent manner (Jonsson et al., 2007a, Jonsson et al., 2007b). The absence of cyp1a induction in adult brains indicate that the altered phenotype is not likely to be caused by direct effects of residual PCB126 on adult brain, but rather is a result of cryptic developmental changes that become evident as behavioral deficits after the animals have reached adulthood.

Dioxin-like PCBs exert their toxicity primarily through the AHR pathway, and we hypothesize that the effects observed here occur subsequent to AHR-mediated disruption of neurodevelopment. The AHR is expressed in the vertebrate brain at multiple life stages (Andreasen et al., 2002, Petersen et al., 2000, Williamson et al., 2005) and has an evolutionarily conserved role in neuronal development (Collins et al., 2008, Huang et al., 2004, Latchney et al., 2013, Qin and Powell-Coffman, 2004). In the zebrafish brain, dioxin exposure was found to cause induction of AHR2 (Andreasen et al., 2002) as well as its associated protein aryl hydrocarbon nuclear translocator (ARNT) (Tanguay et al., 2000). Early exposure of zebrafish embryos to environmentally relevant concentrations of dioxin resulted in reduced brain volume and decreased expression of neurodevelopmental genes in larvae (Hill et al., 2003). In rodents, gestational exposure to dioxin causes AHR-dependent abnormal development in a number of areas in the brain, including the cerebellum, hippocampus, the midbrain and the early region of the forebrain that matures to control advanced brain functions (Collins et al., 2008, Latchney et al., 2013, Tanida et al., 2014, Williamson et al., 2005). These abnormalities often involve changes in neuronal development and establishment of neuron cell fate (Gohlke et al., 2009, Hays et al., 2002, Latchney et al., 2013, Nguyen et al., 2013b). These effects do not occur in AHR-null mice, consistent with a role for AHR in mediating dioxin-induced alteration of neuronal differentiation (Gohlke et al., 2009, Latchney et al., 2013). The AHR has also been implicated in the mechanism of neurodevelopmental toxicity caused by other AHR ligands, such as benzo[a]pyrene (Bouayed et al., 2009, Chen et al., 2012, Chepelev et al., 2015, Vignet et al., 2014). In the present study, expression of cyp1a, an indicator of AHR activation, was induced in embryos and larvae following early exposure to PCB126, demonstrating that the AHR pathway was indeed activated through the first five days of development. It remains to be determined whether similar neurodevelopmental defects can be observed in zebrafish embryos transiently exposed to AHR agonists, and whether there are specific developmental windows of sensitivity for these effects. Experiments using timed exposure to more labile AHR agonists could be useful in this regard. In addition, the relative roles of the three zebrafish AHRs (AHR1a, AHR1b, AHR2; (Andreasen et al., 2002, 
Karchner et al., 2005, Tanguay et al., 1999)) and the specific cellular and molecular mechanisms involved remain to be determined.

Developmental exposure to PCBs and dioxins has been shown to cause alterations in thyroid hormone levels in humans and animal models, and it has been hypothesized that early exposure to these compounds may cause thyroid-dependent alterations in brain development that can subsequently result in impaired cognitive and behavioral functions (reviewed by Schantz and Widholm, 2001). However, the congener-specificity of PCBinduced effects on the thyroid pathway and whether they are directly related to any specific neurobehavioral phenotypes are not completely understood. Our study was not designed to assess the possible role of thyroid disruption in the effects observed; this would be a worthwhile topic for future study.

In conclusion, this study demonstrates the potential long-term and delayed behavioral effects of developmental exposure to low levels of dioxin-like compounds. Our results stress the importance of trial repetition and extended inter-session intervals in order to fully investigate neurobehavioral outcomes. Yet a question remains; is the lack of habituation associated with an anxiogenic effect of developmental PCB126 exposure, or is it a result of direct effects of PCB exposure on learning and/or memory? Although developmental dioxininduced effects on behavior have been demonstrated in mammalian models, the ability to investigate them in zebrafish may prove advantageous for answering this question. Future studies on adult fish that were developmentally exposed to PCB126 or other dioxin-like and non-dioxin-like PCBs will utilize the ever growing diversity of zebrafish behavioral studies, including well established paradigms specific for testing associative (Kalueff and Cachat, 2011b) and non-associative (Wong et al., 2010) learning, as well as other higher cognitive functions (Bailey et al., 2015), evaluating general anxiety levels (Maximino et al., 2010, Parker et al., 2013), and testing the response to stress-inducing situations (Cachat et al., 2010, Eddins et al., 2010). Phenotype anchoring can be done using readily available molecular tools such as gene expression profiling and gene manipulation that will shed light on the relevant molecular pathways and their roles in direct neurodevelopmental toxicity as well as later-life neurobehavioral alterations resulting from developmental exposure.

\section{Acknowledgments}

This work was supported by the Postdoctoral Scholar Program at the Woods Hole Oceanographic Institution (with funding provided by the Townsend Postdoctoral Scholarship Fund, and the John H. Steele Endowment in support of Postdoctoral Research) and by the Woods Hole Center for Oceans and Human Health (NIH grant P01ES021923 and National Science Foundation Grant OCE-1314642 to MEH and NA.). 


\section{Bibliography}

Al-Imari L, Gerlai R. Sight of conspecifics as reward in associative learning in zebrafish (Danio rerio). Behav Brain Res. 2008;189: 216-219.

Andreasen EA, Hahn ME, Heideman W, Peterson RE, Tanguay RL. The zebrafish (Danio rerio) aryl hydrocarbon receptor type 1 is a novel vertebrate receptor. Mol Pharmacol. 2002;62: 234-249.

Bailey J, Oliveri A, Levin ED. Zebrafish model systems for developmental neurobehavioral toxicology. Birth Defects Res C Embryo Today. 2013;99: 14-23.

Bailey JM, Oliveri AN, Levin ED. Pharmacological analyses of learning and memory in zebrafish (Danio rerio). Pharmacol Biochem Behav. 2015.

Bouayed J, Desor F, Rammal H, Kiemer AK, Tybl E, Schroeder H, et al. Effects lactational exposure to benzo[ $\alpha]$ pyrene $(B[\alpha] P)$ on postnatal neurodevelopment, neuronal receptor gene expression and behaviour in mice. Toxicology. 2009;259: 97-106.

Cachat J, Stewart A, Grossman L, Gaikwad S, Kadri F, Chung KM, et al. Measuring behavioral and endocrine responses to novelty stress in adult zebrafish. Nat Protoc. 2010;5: 1786-1799.

Chen CZ, Tang Y, Jiang XJ, Qi YB, Cheng SQ, Qiu CY, et al. Early postnatal benzo(a)pyrene exposure in Sprague-Dawley rats causes persistent neurobehavioral impairments that emerge postnatally and continue into adolescence and adulthood. Toxicol Sci. 2012;125: 248-261.

Chepelev NL, Moffat ID, Bowers WJ, Yauk CL. Neurotoxicity may be an overlooked consequence of benzo[a]pyrene exposure that is relevant to human health risk assessment. Mutat Res: Rev Mutat Res. 2015;764: 64-89.

Collins LL, Williamson MA, Thompson BD, Dever DP, Gasiewicz TA, Opanashuk LA. 2,3,7,8tetracholorodibenzo- $p$-dioxin exposure disrupts granule neuron precursor maturation in the developing mouse cerebellum. Toxicol Sci. 2008;103: 125-136.

Connors SL, Levitt P, Matthews SG, Slotkin TA, Johnston MV, Kinney HC, et al. Fetal mechanisms in neurodevelopmental disorders. Pediatr Neurol. 2008;38: 163-176.

Cowden J, Padnos B, Hunter D, MacPhail R, Jensen K, Padilla S. Developmental exposure to valproate and ethanol alters locomotor activity and retino-tectal projection area in zebrafish embryos. Reprod Toxicol. 2012;33: 165-173.

Crinnion WJ. Polychlorinated biphenyls: persistent pollutants with immunological, neurological, and endocrinological consequences. Altern Med Rev. 2011;16: 5-13.

de Esch C, Slieker R, Wolterbeek A, Woutersen R, de Groot D. Zebrafish as potential model for developmental neurotoxicity testing: a mini review. Neurotoxicol Teratol. 2012a;34: 545-553.

de Esch C, van der Linde H, Slieker R, Willemsen R, Wolterbeek A, Woutersen R, et al. Locomotor activity assay in zebrafish larvae: influence of age, strain and ethanol. Neurotoxicol Teratol. 2012b;34: 425-433.

Eddins D, Cerutti D, Williams P, Linney E, Levin ED. Zebrafish provide a sensitive model of persisting neurobehavioral effects of developmental chlorpyrifos exposure: comparison with nicotine and pilocarpine effects and relationship to dopamine deficits. Neurotoxicol Teratol. 2010;32: 99-108.

Gohlke JM, Stockton PS, Sieber S, Foley J, Portier CJ. AhR-mediated gene expression in the developing mouse telencephalon. Reprod Toxicol. 2009;28: 321-328.

Grandjean P, Landrigan PJ. Developmental neurotoxicity of industrial chemicals. Lancet. 2006;368: 2167-2178.

Grandjean P, Landrigan PJ. Neurobehavioural effects of developmental toxicity. Lancet Neurol. 2014;13: 330-338.

Hany J, Lilienthal H, Roth-Harer A, Ostendorp G, Heinzow B, Winneke G. Behavioral effects following single and combined maternal exposure to PCB 77 (3,4,3 ',4 '-tetrachlorobiphenyl) and PCB 47 $(2,4,2$ ', 4 '-tetrachlorobiphenyl) in rats. Neurotoxicol Teratol. 1999;21: 147-156.

Hays LE, Carpenter CD, Petersen SL. Evidence that GABAergic neurons in the preoptic area of the rat brain are targets of 2,3,7,8-tetrachlorodibenzo-p-dioxin during development. Environ Health Perspect. 2002;110: 369-376. 
Heindel JJ, Vandenberg LN. Developmental origins of health and disease: a paradigm for understanding disease cause and prevention. Curr Opin Pediatr. 2015;27: 248-253.

Hill A, Howard CV, Strahle U, Cossins A. Neurodevelopmental defects in zebrafish (Danio rerio) at environmentally relevant dioxin (TCDD) concentrations. Toxicol Sci. 2003;76: 392-399.

Huang X, Powell-Coffman JA, Jin YS. The AHR-1 aryl hydrocarbon receptor and its co-factor the AHA1 aryl hydrocarbon receptor nuclear translocator specify GABAergic neuron cell fate in $C$. elegans. Development. 2004;131: 819-828.

Huisman M, Koopman-Esseboom C, Fidler V, Hadders-Algra M, van der Paauw CG, Tuinstra LG, et al. Perinatal exposure to polychlorinated biphenyls and dioxins and its effect on neonatal neurological development. Early Hum Dev. 1995;41: 111-127.

Irons TD, Kelly PE, Hunter DL, Macphail RC, Padilla S. Acute administration of dopaminergic drugs has differential effects on locomotion in larval zebrafish. Pharmacol Biochem Behav. 2013;103: 792813.

Jacobson JL, Jacobson SW. Intellectual impairment in children exposed to polychlorinated biphenyls in utero. N Engl J Med. 1996;335: 783-789.

Jacobson JL, Jacobson SW, Humphrey HE. Effects of in utero exposure to polychlorinated biphenyls and related contaminants on cognitive functioning in young children. J Pediatr. 1990;116: 38-45.

Jolous-Jamshidi B, Cromwell HC, McFarland AM, Meserve LA. Perinatal exposure to polychlorinated biphenyls alters social behaviors in rats. Toxicol Lett. 2010;199: 136-143.

Jonsson ME, Jenny MJ, Woodin BR, Hahn ME, Stegeman JJ. Role of AHR2 in the expression of novel cytochrome p450 1 family genes, cell cycle genes, and morphological defects in developing zebra fish exposed to 3,3 ',4,4 ',5-pentachlorobiphenyl or 2,3,7,8-tetrachlorodibenzo- $p$-dioxin. Toxicol Sci. 2007a;100: 180-193.

Jonsson ME, Kubota A, Timme-Laragy AR, Woodin B, Stegeman JJ. Ahr2-dependence of PCB126 effects on the swim bladder in relation to expression of CYP1 and cox-2 genes in developing zebrafish. Toxicol Appl Pharm. 2012;265: 166-174.

Jonsson ME, Orrego R, Woodin BR, Goldstone JV, Stegeman JJ. Basal and 3,3',4,4',5pentachlorobiphenyl-induced expression of cytochrome P450 1A, 1B and $1 \mathrm{C}$ genes in zebrafish. Toxicol Appl Pharm. 2007b;221: 29-41.

Kakeyama M, Endo T, Zhang Y, Miyazaki W, Tohyama C. Disruption of paired-associate learning in rat offspring perinatally exposed to dioxins. Arch Toxicol. 2014;88: 789-798.

Kakeyama M, Tohyama C. Developmental neurotoxicity of dioxin and its related compounds. Ind Health. 2003;41: 215-230.

Kalueff AV, Cachat J. Zebrafish Models in Neurobehavioral Research. New York: Human Press; 2011a.

Kalueff AV, Cachat J. Zebrafish Models in Neurobehavioral Research. New York: Human Press; 2011b.

Kalueff AV, Cachat J. Zebrafish Models in Neurobehavioral Research. New York: Human Press; 2012.

Karchner SI, Franks DG, Hahn ME. AHR1B, a new functional aryl hydrocarbon receptor in zebrafish: tandem arrangement of $a h r 1 b$ and $a h r 2$ genes. Biochem J. 2005;392: 153-161.

Landrigan PJ. Pesticides and polychlorinated biphenyls (PCBs): an analysis of the evidence that they impair children's neurobehavioral development. Mol Genet Metab. 2001;73: 11-17.

Latchney SE, Hein AM, O'Banion MK, DiCicco-Bloom E, Opanashuk LA. Deletion or activation of the aryl hydrocarbon receptor alters adult hippocampal neurogenesis and contextual fear memory. J Neurochem. 2013;125: 430-445.

Lee J, Freeman JL. Zebrafish as a model for developmental neurotoxicity assessment: the application of the zebrafish in defining the effects of arsenic, methylmercury, or lead on early neurodevelopment. Toxics. 2014a;2: 464-495.

Lee J, Freeman JL. Zebrafish as a model for investigating developmental lead $(\mathrm{Pb})$ neurotoxicity as a risk factor in adult neurodegenerative disease: a mini-review. Neurotoxicology. 2014b;43: 57-64.

Leussis MP, Bolivar VJ. Habituation in rodents: a review of behavior, neurobiology, and genetics. Neurosci Biobehav R. 2006;30: 1045-1064. 
Levin ED, Chrysanthis E, Yacisin K, Linney E. Chlorpyrifos exposure of developing zebrafish: effects on survival and long-term effects on response latency and spatial discrimination. Neurotoxicol Teratol. 2003;25: 51-57.

Levin ED, Sledge D, Roach S, Petro A, Donerly S, Linney E. Persistent behavioral impairment caused by embryonic methylphenidate exposure in zebrafish. Neurotoxicol Teratol. 2011;33: 668-673.

Livak KJ, Schmittgen TD. Analysis of relative gene expression data using real-time quantitative PCR and the $2^{-\Delta \Delta C t}$ method. Methods. 2001;25: 402-408.

Lupien SJ, McEwen BS, Gunnar MR, Heim C. Effects of stress throughout the lifespan on the brain, behaviour and cognition. Nat Rev Neurosci. 2009;10: 434-445.

Maaswinkel H, Le X, He L, Zhu LQ, Weng W. Dissociating the effects of habituation, black walls, buspirone and ethanol on anxiety-like behavioral responses in shoaling zebrafish. A 3D approach to social behavior. Pharmacol Biochem Be. 2013;108: 16-27.

MacPhail RC, Brooks J, Hunter DL, Padnos B, Irons TD, Padilla S. Locomotion in larval zebrafish: influence of time of day, lighting and ethanol. Neurotoxicology. 2009;30: 52-58.

Marit JS, Weber LP. Persistent effects on adult swim performance and energetics in zebrafish developmentally exposed to 2,3,7,8-tetrachlorodibenzo-p-dioxin. Aquat Toxicol. 2012;106-107: 131-139.

Maximino C, de Brito TM, Dias CAGD, Gouveia A, Morato S. Scototaxis as anxiety-like behavior in fish. Nat Protoc. 2010;5: 209-216.

Nguyen AT, Nishijo M, Hori E, Nguyen NM, Pham TT, Fukunaga K, et al. Influence of maternal exposure to 2,3,7,8-tetrachlorodibenzo-p-dioxin on socioemotional behaviors in offspring rats. Environ Health Insights. 2013a;7: 1-14.

Nguyen MN, Nishijo M, Nguyen AT, Bor A, Nakamura T, Hori E, et al. Effects of maternal exposure to 2,3,7,8-tetrachlorodibenzo- $p$-dioxin on parvalbumin- and calbindin-immunoreactive neurons in the limbic system and superior colliculus in rat offspring. Toxicology. 2013b;314: 125-134.

Ninkovic J, Bally-Cuif $L$. The zebrafish as a model system for assessing the reinforcing properties of drugs of abuse. Methods. 2006;39: 262-274.

Orito K, Gotanda N, Murakami M, Ikeda T, Egashira N, Mishinia K, et al. Prenatal exposure to 3,3 ',4,4 ',5-pentachlorobiphenyl (PCB126) promotes anxiogenic behavior in rats. Tohoku J Exp Med. 2007;212: 151-157.

Park HY, Hertz-Picciotto I, Sovcikova E, Kocan A, Drobna B, Trnovec T. Neurodevelopmental toxicity of prenatal polychlorinated biphenyls (PCBs) by chemical structure and activity: a birth cohort study. Environ Health. 2010;9: 51.

Parker MO, Brock AJ, Millington ME, Brennan $\mathrm{CH}$. Behavioural phenotyping of casper mutant and 1pheny-2-thiourea treated adult zebrafish. Zebrafish. 2013;10: 466-471.

Patandin S, Lanting Cl, Mulder PGH, Boersma ER, Sauer PJJ, Weisglas-Kuperus N. Effects of environmental exposure to polychlorinated biphenyls and dioxins on cognitive abilities in Dutch children at 42 months of age. J Pediatr. 1999;134: 33-41.

Pean S, Daouk T, Vignet C, Lyphout L, Leguay D, Loizeau V, et al. Long-term dietary-exposure to noncoplanar PCBs induces behavioral disruptions in adult zebrafish and their offspring. Neurotoxicol Teratol. 2013;39: 45-56.

Pena-Llopis S, Brugarolas J. Simultaneous isolation of high-quality DNA, RNA, miRNA and proteins from tissues for genomic applications. Nat Protoc. 2013;8: 2240-2255.

Petersen SL, Curran MA, Marconi SA, Carpenter CD, Lubbers LS, McAbee MD. Distribution of mRNAs encoding the arylhydrocarbon receptor, arylhydrocarbon receptor nuclear translocator, and arylhydrocarbon receptor nuclear translocator- 2 in the rat brain and brainstem. J Comp Neurol. 2000;427: 428-439.

Piedrafita B, Erceg S, Cauli O, Monfort P, Felipo V. Developmental exposure to polychlorinated biphenyls PCB153 or PCB126 impairs learning ability in young but not in adult rats. Eur J Neurosci. 2008;27: 177-182. 
Qin H, Powell-Coffman JA. The Caenorhabditis elegans aryl hydrocarbon receptor, AHR-1, regulates neuronal development. Dev Biol. 2004;270: 64-75.

$R$ Core Team (2015). R: a language and environment for statistical computing. R Foundation for Statistical Computing, Vienna, Austria. URL https://www.R-project.org/.

Salomons AR, van Luijk JAKR, Reinders NR, Kirchhoff S, Arndt SS, Ohl F. Identifying emotional adaptation: behavioural habituation to novelty and immediate early gene expression in two inbred mouse strains. Genes Brain Behav. 2010;9: 1-10.

Schantz SL, Bowman RE. Learning in monkeys exposed perinatally to 2,3,7,8-tetrachlorodibenzo- $p$ dioxin (TCDD). Neurotoxicol Teratol. 1989;11: 13-19.

Schantz SL, Widholm JJ. Cognitive effects of endocrine-disrupting chemicals in animals. Environ Health Perspect. 2001;109: 1197-1206.

Schantz SL, Widholm JJ, Rice DC. Effects of PCB exposure on neuropsychological function in children. Environ Health Perspect. 2003;111: 357-376.

Seegal RF, Schantz SL. Neurochemical and behavioral sequelae of exposure to dioxins and PCBs. In: Schecter A, editor. Dioxins and Health: Springer US; 1994. 409-447 p.

Selderslaghs IW, Hooyberghs J, Blust R, Witters HE. Assessment of the developmental neurotoxicity of compounds by measuring locomotor activity in zebrafish embryos and larvae. Neurotoxicol Teratol. 2013;37: 44-56.

Seo BW, Sparks AJ, Medora K, Amin S, Schantz SL. Learning and memory in rats gestationally and lactationally exposed to 2,3,7,8-tetrachlorodibenzo-p-dioxin (TCDD). Neurotoxicol Teratol. 1999;21: 231-239.

Stewart A, Gaikwad S, Kyzar E, Green J, Roth A, Kalueff AV. Modeling anxiety using adult zebrafish: a conceptual review. Neuropharmacology. 2012;62: 135-143.

Tanguay RL, Abnet CC, Heideman W, Peterson RE. Cloning and characterization of the zebrafish (Danio rerio) aryl hydrocarbon receptor. BBA - Gene Struct Expr. 1999;1444: 35-48.

Tanguay RL, Andreasen E, Heideman W, Peterson RE. Identification and expression of alternatively spliced aryl hydrocarbon nuclear translocator 2 (ARNT2) cDNAs from zebrafish with distinct functions. Biochim Biophys Acta. 2000;1494: 117-128.

Tanida T, Tasaka K, Akahoshi E, Ishihara-Sugano M, Saito M, Kawata S, et al. Fetal exposure to 2,3,7,8-tetrachlorodibenzo-p-dioxin transactivates aryl hydrocarbon receptor-responsive element III in the tyrosine hydroxylase immunoreactive neurons of the mouse midbrain. J Appl Toxicol. 2014;34: 117-126.

Thompson RF, Spencer WA. Habituation: a model phenomenon for the study of neuronal substrates of behavior. Psychol Rev. 1966;73: 16-43.

Tierney KB. Behavioural assessments of neurotoxic effects and neurodegeneration in zebrafish. Biochim Biophys Acta. 2011;1812: 381-389.

Truong L, Mandrel D, Mandrell R, Simonich M, Tanguay RL. A rapid throughput approach identifies cognitive deficits in adult zebrafish from developmental exposure to polybrominated flame retardants. Neurotoxicology. 2014a;43: 134-142.

Truong L, Reif DM, St Mary L, Geier MC, Truong HD, Tanguay RL. Multidimensional in vivo hazard assessment using zebrafish. Toxicol Sci. 2014b;137: 212-233.

Vignet C, Devier MH, Le Menach K, Lyphout L, Potier J, Cachot J, et al. Long-term disruption of growth, reproduction, and behavior after embryonic exposure of zebrafish to PAH-spiked sediment. Environ Sci Pollut Res. 2014;21: 13877-13887.

Vreugdenhil HJ, Lanting $\mathrm{Cl}$, Mulder PG, Boersma ER, Weisglas-Kuperus N. Effects of prenatal PCB and dioxin background exposure on cognitive and motor abilities in Dutch children at school age. J Pediatr. 2002;140: 48-56.

Williamson MA, Gasiewicz TA, Opanashuk LA. Aryl hydrocarbon receptor expression and activity in cerebellar granule neuroblasts: implications for development and dioxin neurotoxicity. Toxicol Sci. 2005;83: 340-348. 
Wong K, Elegante M, Bartels B, Elkhayat S, Tien D, Roy S, et al. Analyzing habituation responses to novelty in zebrafish (Danio rerio). Behav Brain Res. 2010;208: 450-457.

Xu X, Lamb C, Smith M, Schaefer L, Carvan MJ, Weber DN. Developmental methylmercury exposure affects avoidance learning outcomes in adult zebrafish. J Toxicol Environ Health A. 2012;4: 85-91.

Zimmer KE, Gutleb AC, Lyche JL, Dahl E, Oskam IC, Krogenaes A, et al. Altered stress-induced cortisol levels in goats exposed to polychlorinated biphenyls (PCB 126 and PCB 153) during fetal and postnatal development. J Toxicol Environ Health A. 2009;72: 164-172. 


\section{Figure captions}

Fig. 1 Overview of experimental timeline and design. Zebrafish embryos were exposed to PCB126 or vehicle control for $20 \mathrm{~h}$ from 4 until $24 \mathrm{hpf}$, when the fish were transferred to clean water. RNA was extracted from embryos and larvae at 24 and $120 \mathrm{hpf}$, respectively. Larval locomotor activity was tested at 7 and $14 \mathrm{dpf}$. Adult fish anxiety-related behavior was tested at the age of 4 months using the novel tank and shoaling paradigms followed by dissection and RNA extraction of brain tissue.

Fig. 2 Larval locomotor activity in response to changes in light conditions following developmental exposure to PCB126, as tested at $7 \mathrm{dpf}(\mathrm{A})$ and $14 \mathrm{dpf}(\mathrm{B})$. The fish were recorded for 42 minutes, starting with 5 minutes in the dark, followed by 15 minutes in $50 \%$ light, 15 minutes in $100 \%$ light and 7 minutes in the dark. Grey boxes indicate transitions between lighting conditions.

Fig. 3 Effect of developmental exposure to PCB126 on group shoaling behavior. (A) Experimental set-up and demonstration of high and low clustering and cluster score calculations. Low group cohesion, with a maximum of two fish in one section and a total number of four sections in which the fish were dispersed, results in a cluster score of 0.5 (left picture); a high level of cohesion, with a maximum number of four fish in one section and a total number of only two sections occupied by fish, results in a cluster score of 2 (right picture). (B) A boxplot representation of the mean cluster scores calculated for each of the experimental groups in trials 1 and 2. a - significant difference from the vehicle control mean cluster score in Trial 1. b- significant difference from the $0.3 \mathrm{nM}$ PCB126-exposed fish mean cluster score in Trial 1.

Fig. 4 Impairment of adult zebrafish inter-session habituation to the novel tank assay caused by developmental exposure to PCB126. Fish were individually introduced to the test tank and video recorded for $10 \mathrm{~min}$. Three trials were conducted separated by two-week intervals. Mean percent time spent in the bottom zone $(A)$ and the initial latency (in sec) to reach the upper zone $(B)$ were calculated for each experimental group for the entire trial period. Within-trial differences are marked with lower case letters and between-trial differences are marked with an asterisk.

Fig. 5 Impairment of adult zebrafish intra-session habituation to the novel tank assay caused by developmental exposure to PCB126. (A) Mean percent time spent in the bottom zone by 2-minute segments. Broken horizontal line marks $50 \%$ time in bottom zone across trials. Significant differences are denoted by an asterisk. (B) Representative tracking from each experimental group for the first 2 minutes of Trial 3 . The bottom zone is shaded in light grey.

Fig. 6 Developmental exposure to PCB126 did not affect adult zebrafish swimming performance. Total distance travelled in centimeters was calculated for each experimental 
group for the entire trial period. Different letters represents significant changes from vehicle control.

Fig. 7 Cyp1a expression is induced in embryos and larvae but not adult brains of zebrafish developmentally exposed to PCB126. Relative quantification of cyp1a expression in $24 \mathrm{hpf}$ embryos, $120 \mathrm{hpf}$ larvae and behavior-tested adult brain tissue using qRT-PCR. $\beta$-actin was used as an internal standard. The $\Delta \Delta \mathrm{Ct}$ method was used to determine the fold change in gene expression. Significant difference from vehicle control is marked with an asterisk. 
Table 1 Developmental PCB126 exposures and following experiments

\begin{tabular}{|c|c|c|c|c|}
\hline & Treatments & $\begin{array}{l}\text { Sampling for } \\
\text { RNA extraction }\end{array}$ & $\begin{array}{l}\text { Larval } \\
\text { behavior }\end{array}$ & $\begin{array}{c}\text { Adult } \\
\text { behavior }\end{array}$ \\
\hline Exposure 1 & Vehicle control, 0.3 nM PCB126 & $24 \mathrm{hpf}$ & - & - \\
\hline Exposure 2 & $\begin{array}{l}\text { Vehicle control, } 0.3 \text { nM PCB126, } \\
0.6 \text { nM PCB126, 1.2 nM PCB126 }\end{array}$ & - & $7 \mathrm{dpf}$ & - \\
\hline Exposure 3 & $\begin{array}{l}\text { Non-exposed, vehicle control, } \\
\text { 0.3 nM PCB126, 0.6 nM PCB126, } \\
1.2 \text { nM PCB126 }\end{array}$ & $120 \mathrm{hpf}$ & $14 \mathrm{dpf}$ & 4 months \\
\hline
\end{tabular}


Table 2 Number of individuals tested in each of the novel tank trials

\begin{tabular}{c||ccccc} 
& $\begin{array}{c}\text { Non- } \\
\text { exposed } \\
\text { control }\end{array}$ & $\begin{array}{c}\text { Vehicle } \\
\text { control }\end{array}$ & $\begin{array}{c}\mathbf{0 . 3} \mathbf{n M} \\
\text { PCB126 }\end{array}$ & $\begin{array}{c}\mathbf{0 . 6} \mathbf{n M} \\
\text { PCB126 }\end{array}$ & $\begin{array}{c}\mathbf{1 . 2} \mathbf{n M} \\
\text { PCB126 }\end{array}$ \\
\hline \hline Total & 9 & 10 & 14 & 10 & 8 \\
\hline Trial 1 & 9 & 9 & 12 & 8 & 8 \\
Trial 2 & - & 10 & 13 & 9 & 7 \\
Trial 3 & 9 & 9 & 14 & 10 & 8
\end{tabular}

The total number of fish in each treatment group is presented in the top row. 


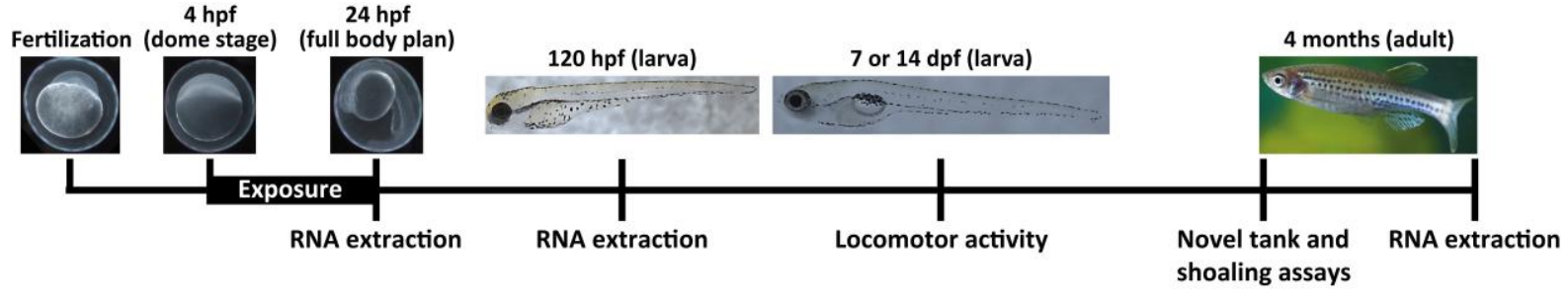

Figure 1 
(A)

$7 \mathrm{dpf}$

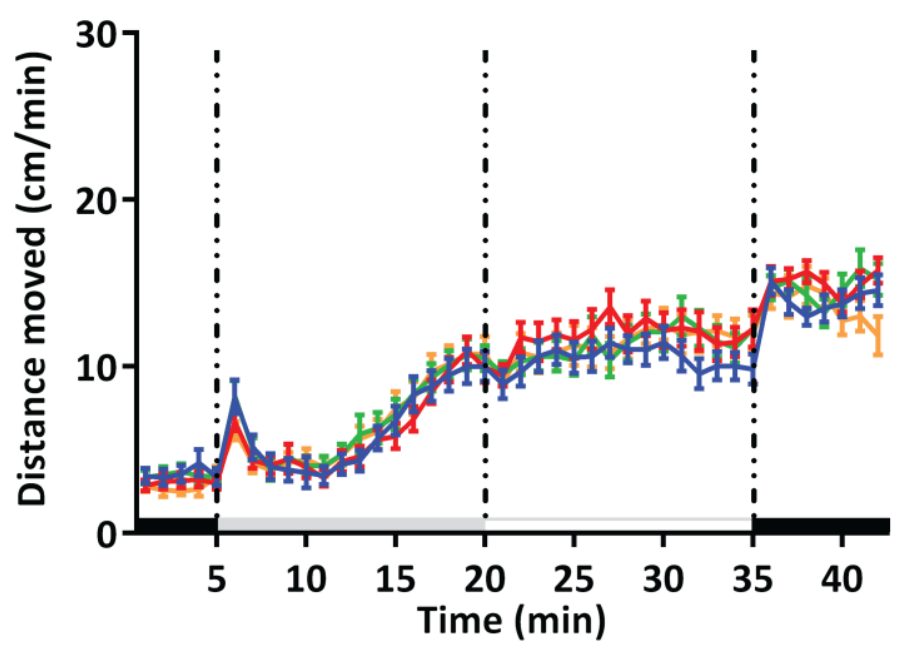

(B)

$14 \mathrm{dpf}$

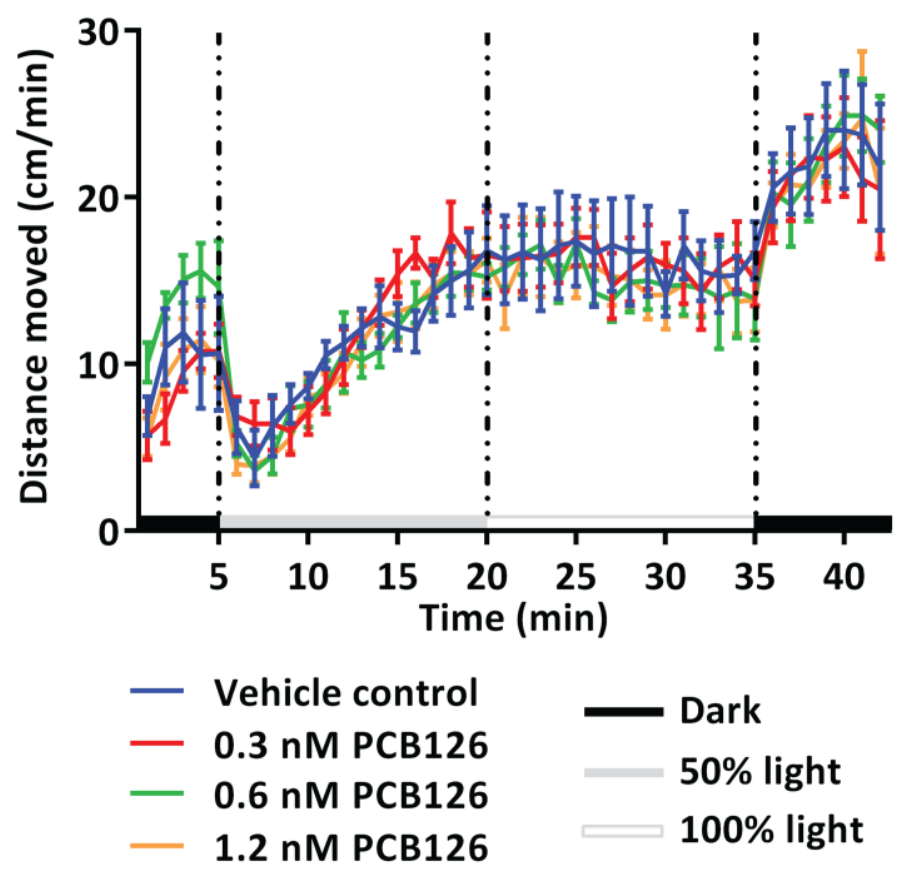

Figure 2 
(A) Cluster score $=2 / 4=0.5$

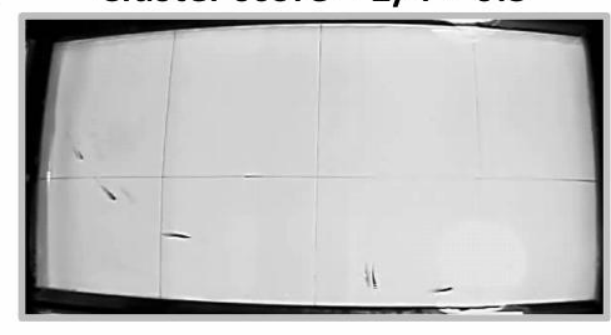

(B)

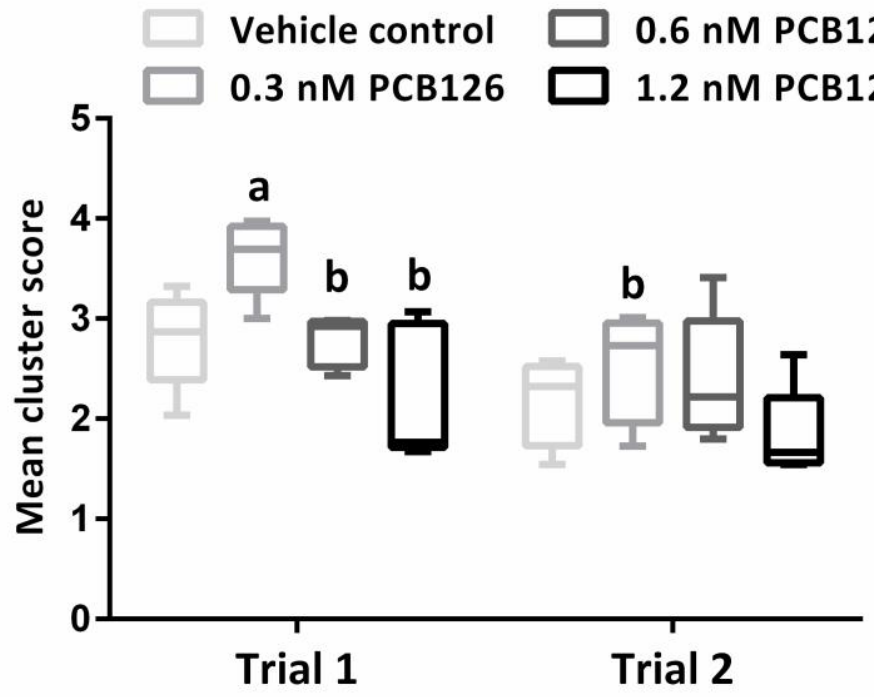

Cluster score $=4 / 2=2$

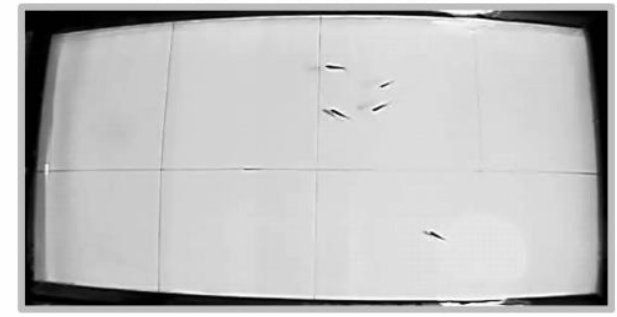

Figure 3 
(A) Percent time in 'bottom zone'

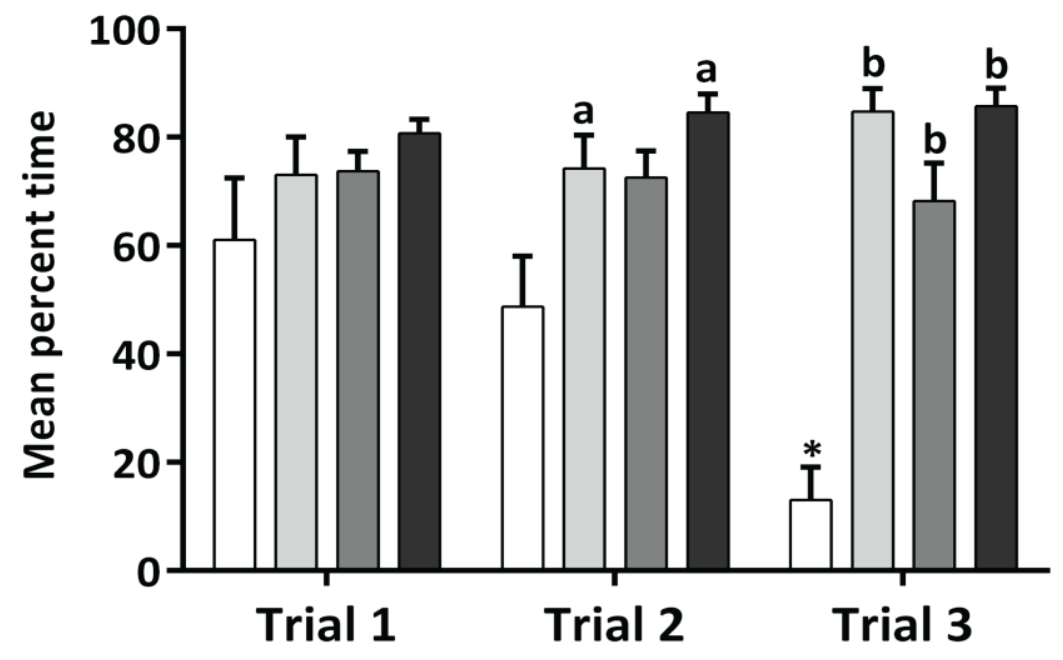

(B) Latency to upper zone

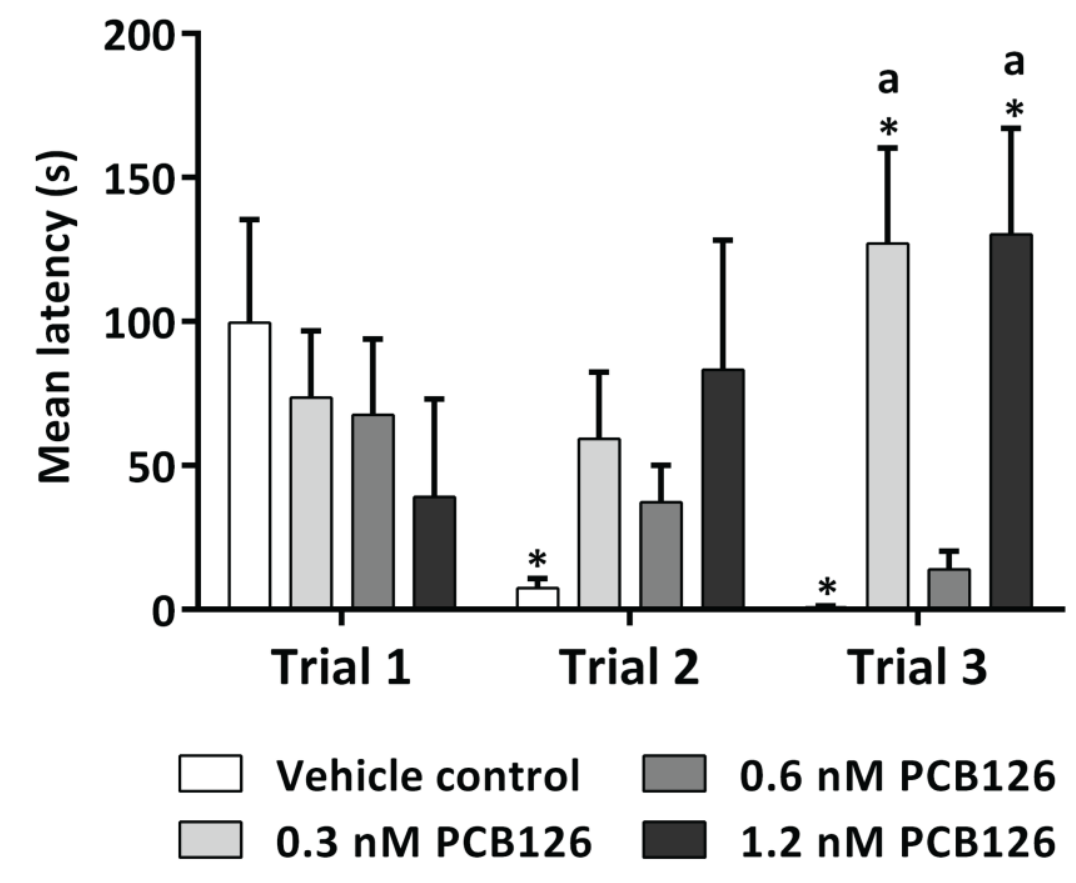

Figure 4 
(A) Percent time spent in 'bottom zone'

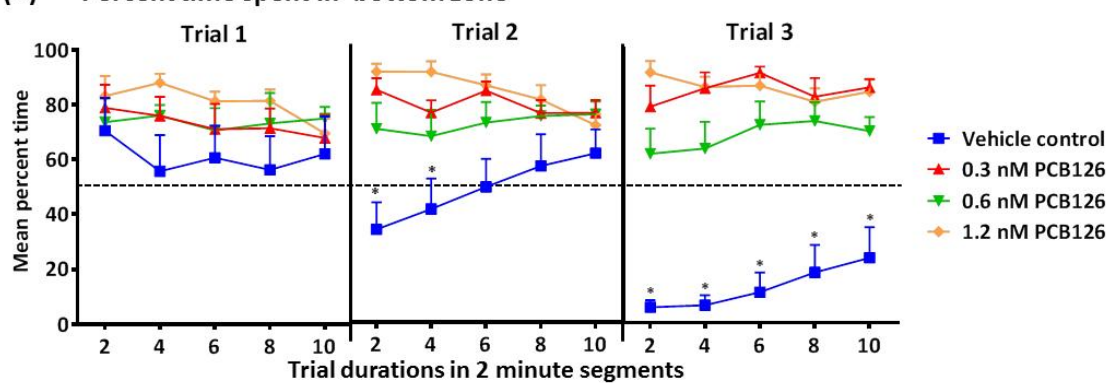

(B) Representative tracking of the first 2 minutes in Trial 3

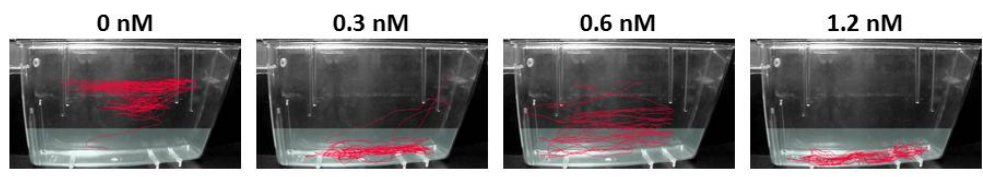

Figure 5 
Mean total distance travelled

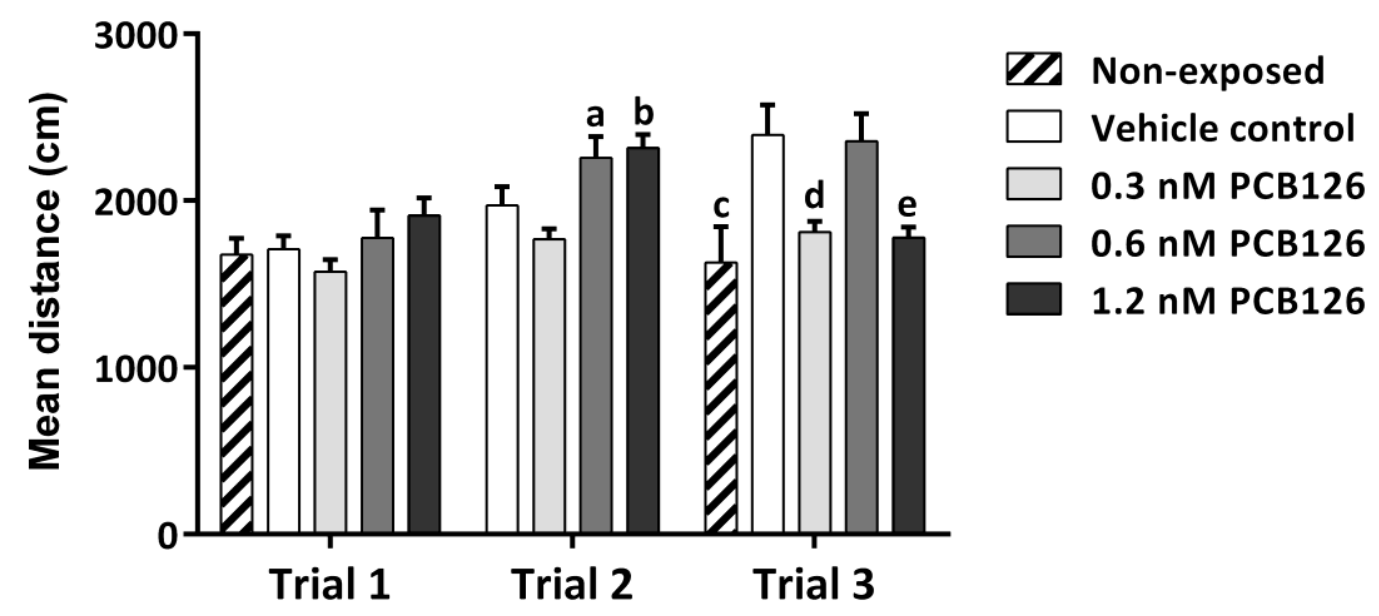

Figure 6 
Cyp1a expression

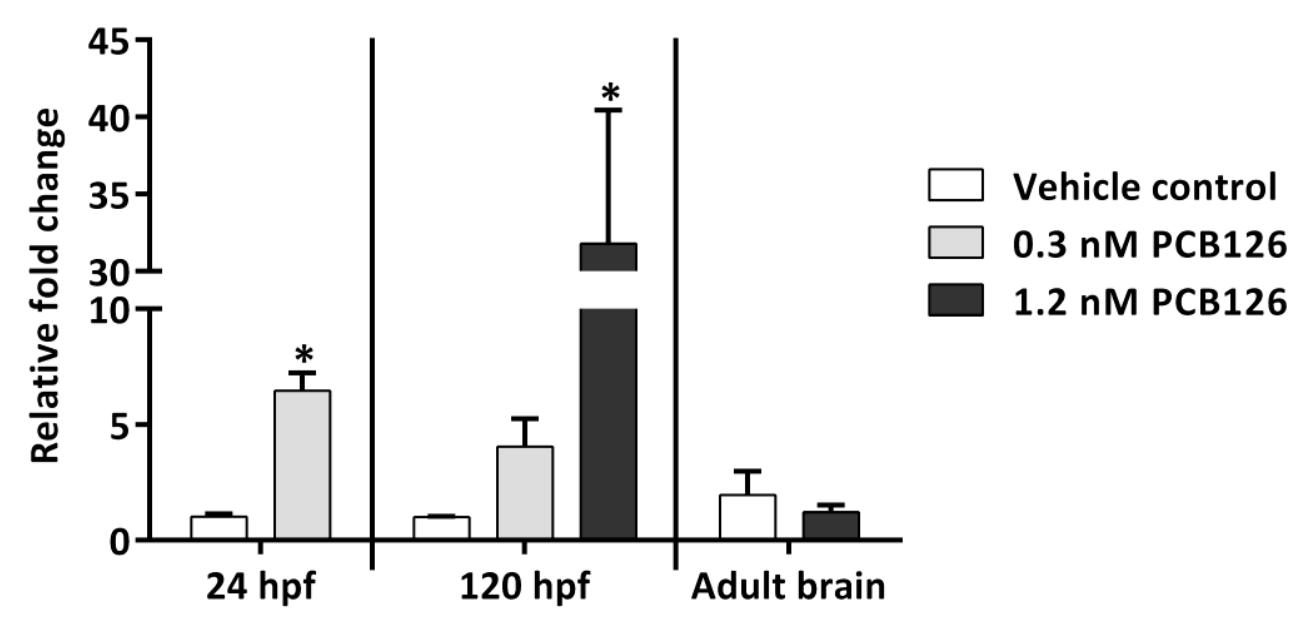

Figure 7 